\title{
Meeting the Challenge: Prevention of Pneumococcal Disease with Conjugate Vaccines
}

\author{
Irma Gabriela Echániz-Avilés, M. Sc., ${ }^{(1)}$ Fortino Solórzano-Santos, D r. ${ }^{(2)}$
}

\begin{abstract}
Echániz-Avilés IG, Solórzano-Santos F. Meeting the Challenge: Prevention of Pneumococcal Disease with Conjugate Vaccines.

Salud Publica Mex 2001;43:352-367.

The Spanish version of this paper is available at: http://www.insp.mx/salud/index.html
\end{abstract}

\begin{abstract}
A bstract
Streptococcus pneumoniae is one of the leading causes of both invasive and noninvasive diseases in the pediatric population and continues to represent a significant public health burden worldwide. The increasing incidence of antibioticresistant strains of the pathogen has complicated treatment and management of the vario us pneumo coccal disease manifestations. Thus, the best management strategy may be the prevention of pneumococcal diseases through vaccination. Although several pneumococcal conjugate vaccines have been clinically studied in infants and children, only a 7-valent conjugate vaccine (PNCRM7; Prevnar ${ }^{\circledR}$ ) Prevenar ${ }^{\circledR}$ ) is currently approved for the prevention of invasive disease. Vaccination with PN CRM7 is safe and effective in infants and young children. Routine vaccination with the conjugate vaccine could improve outcomes by safeguarding against the development of antibiotic-resistant strains of S. pneumoniae, thus simplifying the management of pneumococcal disease. Additionally, the overall costs associated with the treatment of pneumococcal diseases could be substantially reduced, particularly in developing countries. The time has come for fully applying this new advancement against S. pneumoniae, to benefit the children of the world. The Spanish version of this paper is available at: http://www.insp.mx/salud/index.html
\end{abstract}

Key words: pneumococcal infections; Streptococcus pneumoniae; infant; vaccines

\author{
Echániz-Avilés IG, Solórzano-Santos F. \\ Al encuentro del reto: prevención \\ de la enfermedad neumocócica \\ con vacunas conjugadas. \\ Salud Publica Mex 2001;43:352-367. \\ El texto completo en español de este artículo está \\ disponible en: http://www.insp.mx/salud/index.html
}

\section{Resumen}

Streptococcus pneumoniae es uno de los principales agentes causantes de enfermedades invasoras y no invasoras en la población pediátrica y sigue representando uno de los principales problemas de salud pública a nivel mundial. La incidencia creciente de cepas resistentes a diversos antimicrobianos ha complicado el tratamiento y manejo de varias de las manifestaciones de la enfermedad neumo cócica. Con éstas consideraciones, la mejor estrategia de manejo es la prevención de éstas enfermedades a través de la vacunación. A pesar de que se han estudiado diversas vacunas neumocócicas conjugadas en niños, solo una vacuna 7-valente conjugada (PN C RM 7; Prevnar ${ }^{\circledR} /$ Prevenar $^{\circledR}$ ) se encuentra aprobada para la prevención de enfermedades invasoras en niños. La vacunación con PN C RM7 es segura y efectiva en infantes y niños pequeños. La vacunación rutinaria con la vacuna conjugada podría mejorar el resultado de los tratamientos, previniendo el desarrollo de cepas resistentes de S. pneumoniae y simplificando el manejo de las enfermedades neumocócicas. Además, los costos asociados con el tratamiento de estas enfermedades se reduciría substancialmente, particularmente en los países en desarrollo. El tiempo ha llegado para aplicar este nuevo avance contra S. pneumoniae y obtener todos los beneficios que así merecen los niños del mundo. El texto completo en español de este artículo está disponible en: http://www.insp.mx/salud/index.html

Palabras clave: infecciones neumocócicas; Streptococcus pneumoniae; lactante; vacunas

(1) Instituto $\mathrm{N}$ acional de Salud Pública, Cuernavaca, México.

(2) Hospital de Pediatría, Centro Médico N acional Siglo XXI, Instituto Mexicano del Seguro Social, México, D.F.

Received on: March 2,2001 • Accepted: June 11.2001

Reprint requests to: Gabriela Echániz-Avilés, Departamento de Epidemiología C línica, Instituto $N$ acional de Salud Pública. Av. Universidad 655, Colonia Santa María A huacatitlán, 62508 Cuernavaca, Morelos, México.

E-mail: igechaniz@correo.insp.mx 
S treptococcus pneumoniae has become one of the most $S$ important bacterial pathogens in infants and children, especially in populations where the Haemophilus influenzae type b (Hib) vaccine has been introduced. ${ }^{1}$ It is the leading cause of bacterial pneumonia, bacteremia, and bacterial otitis media, and one of the 3 most common causes of bacterial meningitis in children younger than 5 years of age. ${ }^{2,3}$ Worldwide, approximately 4 million children die each year from pneumonia; 1 million of these deaths have been attributed to S. pneumoniae. ${ }^{4}$ Most of these deaths occur in children younger than 1 year of age living in developing countries. ${ }^{5,6}$ S. pneumoniae represents the most common cause of community-acquired pneumonia (CAP) in the United States, accounting annually for 500000 cases of pneumonia and 100000 to 135000 hospitalizations. ${ }^{7}$

Disease rates associated with $S$. pneumoniae are particularly high in young children, the elderly, and patients with predisposing conditions such as asplenia, chronic medical conditions (e.g., heart disease, lung disease, kidney disease, diabetes, alcoholism) or immunosuppressive illnesses, particularly acquired immunodeficiency syndrome (AIDS). These same groups are at greater risk of pneumococcal invasion to the bloodstream and central nervous system, and thus, are at greater risk of death. ${ }^{8,9}$

The incidence of pneumococcal infection varies geographically, but increasing rates have been observed in many developed and developing countries. In a survey of 560 pneumococcal blood isolates from patients in Southern Sweden between 1981 and 1996, the incidence of pneumococcal bacteremia increased from 5.2 to 15.2/100 000 per year. ${ }^{10}$ In Denmark, the incidence of invasive pneumococcal disease (IPD) has increased more than 10 times over the last two decades, as judged by the number of isolates of $S$. pneumoniae obtained from blood and cerebrospinal fluid. ${ }^{11}$ Since 1993, surveillance studies in Latin American countries -coordinated by the Pan American Health Organization (PAHO) and performed by the Sistema Regional de Vacunas (SIREVA)-network- have revealed a high incidence of pneumonia and meningitis in children younger than two years of age. Children of this age group are more likely to be infected by pneumococci and have a decreased susceptibility to penicillin than older children. ${ }^{12-19}$

Considering the development of multivalent pneumococcal conjugate vaccines and the results of the first large clinical trial of a pneumococcal 7-valent conjugate vaccine (PNCRM7; Prevenar ${ }^{\circledR} /$ Prevnar $^{\circledR}$ ), the objectives of this article are to: a) review the characteristics and methods of transmission/carriage of $S$. pneumoniae; b) review the clinical epidemiology of pneumococcal diseases (both invasive and noninvasive); c) describe the rationale for vaccination against this pathogenic organism; and d) review the efficacy of the pneumococcal conjugate vaccines currently under investigation or commercially available.

\section{The Pathogen}

S. pneumoniae has been one of the most extensively studied microorganisms since its first isolation in 1881 . In 1928, Griffith observed that when heat-killed encapsulated pneumococci and live strains constitutively lacking any capsule were concomitantly injected into mice, the nonencapsulated pneumococci could be converted into the encapsulated form with the same capsular type as the heat-killed strain. ${ }^{20}$ Years later, the nature of this "transforming principle" was shown to be DNA. ${ }^{21,22}$ Other important discoveries about $S$. pneumoniae resulted from investigations in: a) the therapeutic efficacy of penicillin; $b$ ) the role of the bacterial capsule in resistance to phagocytosis; c) the ability of polysaccharides (PS) to induce antibodies; d) the first demonstration of antigen-specific tolerance or immunologic unresponsiveness; e) the discovery of regulatory thymus-derived $\mathrm{T}$ lymphocytes; and $\mathrm{f}$ ) the recognized use of PS antigens as vaccines..$^{22,23}$

Pneumococci are lancet-shaped gram-positive bacteria that grow in pairs or short chains. The capsule of the bacteria consists of high-molecular weight polymers of repeating oligosaccharides, which contain between 2 and 8 monosaccharides. The capsule has long been recognized as the major virulence factor of S. pneumoniae. On the basis of difference in capsular structure, pneumococci can be divided into about 40 serogroups and 90 serotypes. ${ }^{24}$ The Danish nomenclature classifies serotypes according to structural and antigenic characteristics. The distribution of serotypes isolated from adults differs substantially from those isolated from children. Geographic and age-related differences in the incidence of certain S. pneumoniae serogroups have led to the proposal that, from an epidemiologic standpoint, each should be considered as a separate pathogen..$^{25}$

\section{Transmission and Carriage of S. pneumo- niae}

S. pneumoniae commonly colonizes the nasopharynx asymptomatically in healthy children and adults. ${ }^{26,27}$ This encapsulated potential pathogen is considered a constituent of the normal upper respiratory flora in humans and the main source of person-to-person transmission. Pneumococcal infections are preceded by bac- 
terial colonization of the nasopharyngeal mucosa, ${ }^{28}$ where the bacteria can persist as part of the commensal flora without causing disease.

Nasopharyngeal carriage of S. pneumoniae is more common in young children than adults, and children play an important role in the transmission of pneumococcal disease in the community, due to this high carriage rate and the method of transmission (respiratory droplets). Furthermore, children influence carriage rates in adults. Colonization is generally inversely proportional to the patient's age. According to Fedson, ${ }^{29}$ pneumococcal carriage in adults without children is $6 \%$, compared with carriage from $18 \%$ to $30 \%$ among adults with children. Carriage in preschool children is as high as $60 \%$, in primary school children, $35 \%$, and in high school students, $25 \%$. The duration of carriage varies, depending on the host's age and the serotype of the colonizing strain; carriage typically ranges between 1 and 17 months. ${ }^{28}$ The factors responsible for the transition from carriage to disease include the ability for recognition of and attachment to human nasopharyngeal cells and internalization to other body sites. Other events, often derived from the host, may contribute to the development of symptoms referable to the infected site. An excellent review of the molecular events contributing to targeting pneumococci to various sites of infection and the development of symptomatic pneumococcal disease was recently published by Tuomanen and Masure. ${ }^{30}$

Although antibiotic treatment is considered an important risk factor for nasopharyngeal carriage of antibiotic-resistant pneumococci, few studies have evaluated the immediate effect of antibiotic treatment on nasopharyngeal colonization. Dagan and associates investigated the dynamics of pneumococcal nasopharyngeal colonization in pediatric patients during the first few days of treatment with cefaclor, cefuroximeaxetil, azithromycin, or amoxicillin/clavulanate. ${ }^{31}$ Results indicated that cefuroxime-axetil reduced carriage of pneumococci from $67 \%$ on Day 1 to $31 \%$ on Days 4 or 5 . In contrast, cefaclor did not reduce pneumococci carriage over this period. Importantly, neither cefuroxime-axetil nor cefaclor significantly reduced carriage of penicillin-resistant pneumococci. Pneumococci were isolated from the nasopharynx of $57 \%$ of azithromycin recipients on Day 1 of treatment; $25 \%$ of isolates were azithromycin-resistant. The study also showed that on Days 4 or 5 , a new serotype was isolated in $16 \%$ of patients, $84 \%$ of which were resistant to the respective antibiotic class. These results suggested that significant changes in nasopharyngeal colonization of pneumococcal species occurred early during treatment, with a rapid emergence of antibiotic-resistant strains.

\section{Pneumococcal Antimicrobial Resistance}

Contributing to the urgency of pneumococcal disease prevention is the increasing resistance of S. pneumoniae to penicillin and other commonly used antibiotics, including cephalosporins and macrolides. According to the National Committee for Clinical Laboratory Standards, strains with a minimal inhibitory concentration (MIC) of $0.1 \mu \mathrm{g} / \mathrm{ml}$ to $1.0 \mu \mathrm{g} / \mathrm{ml}$ are defined as having intermediate resistance to penicillin, and strains with an MIC of $2.0 \mu \mathrm{g} / \mathrm{ml}$ or greater are considered highly or fully resistant. ${ }^{32}$ Highly resistant strains are more likely to be resistant to other antibiotics such as erythromycin, tetracycline, chloramphenicol, and trimethoprim-sulfamethoxazole. ${ }^{33}$

Antibiotic-resistant pneumococci are being isolated at an increasing rate, and they have become a serious worldwide problem. Investigators in Boston first reported clinical resistance to penicillin in S. pneumoniae in 1965, but did not recognize the significance of that resistance. ${ }^{34,35}$ Subsequently, this phenomenon was reported in Australia in 1967 and in South Africa in 1977, where strains with both a high level of penicillin resistance and multiple antibiotic resistances were reported. Penicillin resistance spread rapidly throughout the world in the 1980s, mainly in South Africa, ${ }^{36,37}$ Spain, ${ }^{38}$ Hungary, ${ }^{39}$ Czechoslovakia, ${ }^{40,41}$ Asia $^{42}$ the United States of America (USA), ${ }^{43,44}$ Australia, ${ }^{45}$ and other European countries. ${ }^{4-48}$

In Latin American countries (i.e., Argentina, Brazil, Colombia, Chile, Mexico, and Uruguay), the SIREVA network in 1998 studied 1649 sterile-site isolates from children younger than 5 years of age. The study reported that overall, $24.9 \%$ of isolates had diminished susceptibility to penicillin; $16.7 \%$ had intermediate resistance, and $8.3 \%$ had high-level resistance. ${ }^{12}$ The same group had recently reported an overall resistance to penicillin of $34.2 \%$; the lowest resistance to penicillin was reported in Brazil (22.3\%) and the highest in Mexico $(49.4 \%)$ among pediatric invasive pneumococcal isolates. $^{19}$

The first multiple resistant strains of pneumococci were found in children; since then, resistant strains have been shown to be more common in children than in adults. The reason for this association is unclear, but probably reflects the widespread use of antibiotics in children, who more frequently carry pneumococci than adults. This affords a greater chance of conditions conducive to transformation occurring in the nasopharynx of children. ${ }^{49,50}$ Penicillin therapy reduces the carriage of penicillin-susceptible strains in children, but often does not eliminate them. ${ }^{51}$ Because such therapy also selects for colonization of the nasopharynx of children with resistant strains, the coexistence of resistant 
and susceptible strains is favored by penicillin therapy. In multiply resistant strains, exposure to one antibiotic, for example, trimethoprim-sulfamethoxazole, may select for penicillin resistance more readily than does penicillin therapy itself. ${ }^{33,52}$

An analysis of the evolution of pneumococci suggests that the global increase in the incidence of penicillin-resistant pneumococci involves at least two processes. The first process is the importation and spread of a small number of resistant clones, with advantages over local strains, in an environment in which antibiotics are often misused. ${ }^{53-55}$ The second is the in vivo selection of indigenous strains with modified penicillin-binding proteins $(p b p),{ }^{56}$ either by replacement of part of $p b p$ genes by interspecies or homologous recombinational events, or by the acquisition of point mutations in $p b p$ genes. ${ }^{52,57,58}$ Different non- $p b p$ resistance mechanisms have been described for antimicrobial resistance of pneumococci, ${ }^{59,60}$ and others that are under investigation that might play an important role in the dissemination of antimicrobial resistance, with severe clinical consequences. ${ }^{61}$

In Latin American countries, studies from the SIREVA network done as part of a collaborative project with Rockefeller University in New York, have shown the presence of resistant international clones circulating in the region, mainly the Spanish 23F clone in Mexico and Colombia ${ }^{62,63}$ and the French 14 clone in Uruguay and Argentina. ${ }^{64,65}$ This suggests that a major part of the antimicrobial resistance within the region is due to the spread of a limited number of pneumococcal clones. ${ }^{66}$

\section{Clinical Epidemiology of Pneumococcal Diseases}

Infections of the large and lower airways (pneumonia), upper respiratory tract (sinusitis), and auditory canal (otitis media) compose the vast majority of S. pneumoniae-associated disease (Figure 1). ${ }^{7}$ Although severe pneumococcal disease (e.g., necrotizing pneumonia, meningitis, and bacteremia) makes up a smaller disease group, these invasive infections cause the preponderance of $S$. pneumoniae-related mortality. Independent of race, children younger than two years experience a 10-fold increased incidence of bacteremia compared with matched adult populations., $, 12,67$

Bacterial pneumonia most commonly occurs in the very young and the elderly; the spectrum of disease varies from mild to life threatening. Complications may include empyema, a self-limited pleural effusion, or extra pulmonary manifestations (e.g., bacteremia, meningitis). ${ }^{68}$ S. pneumoniae, as an important cause of pedi-

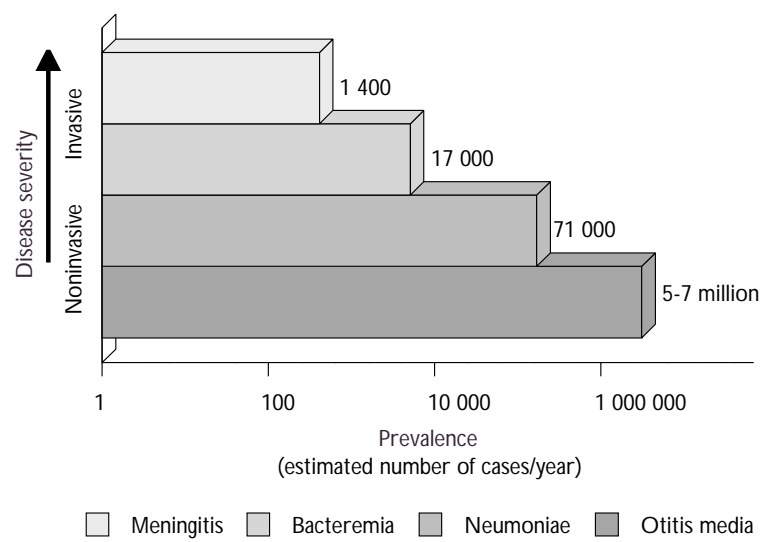

Figure 1. In the United States of America, S. pneuM ONIAE CONTINUES TO BE ASSOCIATED WITH A SIGNIFICANT BURDEN ON THE HEALTH CARE SYSTEM FOR BOTH INVASIVE AND NONINVASIVE DISEASE ${ }^{7}$

atric $\mathrm{CAP}$, has been demonstrated in European and North American settings. In Finland, in order to investigate the etiology of pediatric $\mathrm{CAP}$, a prospective, population-based study was conducted on the total population younger than 15 years of age $(n=8851)$ in four municipalities. The number of patients was 201. Chest radiographs were available for all cases and paired sera for serologic assays were available for over $90 \%$ of cases. The methods included assays for antibody response to three pneumococcal antigens, specific pneumococcal immune complex assays, and conventional antibody tests for mycoplasmal, chlamydial, and viral infections. Serologic evidence of specific microbial etiology was obtained in $133(66 \%)$ of the pneumonia patients. Bacterial infection was diagnosed in 102 cases (51\%) and viral infection in 51 cases (25\%). $S$ pneumoniae was the most common agent with 57 cases $(28 \%)$, followed by Mycoplasma pneumoniae (22\%), respiratory syncytial virus (21\%) and Chlamydia spp. $(14 \%)$. H. influenzae was identified in only $6 \%$ and Moraxella catarrhalis in only 3\% of the children. More than one specific infection was found in 51 patients $(25 \%)$. The proportion of pneumococcal cases varied by age from $24 \%$ to $36 \%$. Consistant with the Finnish results, Wubbel and colleagues in USA identified etiologic agents in ambulatory pediatric patients (6 months to 16 years of age) with CAP, presenting to an emergency medical center in Texas. ${ }^{69}$ They used culturing, PCR, and serology to verify the bacterial pathogen in $43 \%$ of patients in the study. Their results attributed infection to $S$. pneumoniae in $27 \%$ of patients, 
followed by M. pneumoniae in 7\%, and Chlamydia pneumoniae in $6 \%$.

The incidence and prevalence of acute and chronic sinusitis remain to be defined, and the criteria for diagnosis vary widely. Between $0.5 \%$ and $5 \%$ of upper respiratory tract infections may be complicated by acute sinusitis; in these cases, S. pneumoniae, nontypeable $H$. influenzae, and M. catarrhalis are the most common etiologic agents. ${ }^{70-73}$

Otitis media, the most common respiratory tract infection of infancy and early childhood, is primarily caused by three pathogens: S. pneumoniae, nontypeable $H$. influenzae, and to a lesser extent, M. catarrhalis. Episodes of otitis media are generally managed with antibacterial agents. ${ }^{74}$ S. pneumoniae is the pathogen most often implicated in otitis media $(35 \%-40 \%$ of cases) and the one least likely to resolve without treatment. ${ }^{75-77}$ The disease affects at least 7 out of every 10 children; one third experience repeat episodes, and $5 \%$ to $10 \%$ of the cases develop chronic otitis media with effusion. ${ }^{78}$ In many children, acute otitis media initiates the continuum of otitis media, leads to chronic otitis media with effusion, and in some cases, to chronic tissue sequelae (i.e., mucosal granulation, mastoiditis, ossicular erosion and fixation, and cholesteatoma). ${ }^{78,79}$ Subject of the current birth cohort will have had a total of 9.3 million episodes of acute otitis media by the time they reach two years of age ${ }^{80}$ In USA, the total annual treatment costs for otitis media and otitis media with effusion alone may exceed $\$ 5$ billion in children younger than five years old. ${ }^{75,81}$

Multiresistant pneumococcal strains represent an important problem in the treatment of otitis media. The increasing rate of resistance to antibiotic drugs is associated with a decreased rate of eradication of pathogens from middle ear fluid, which in turn, is associated with clinical failure. A bacteriologic cure rate of $80 \%$ to $85 \%$ is observed for S. pneumoniae and nontypeable $H$. influenzae when serum concentrations exceed the MIC for $40 \%$ to $50 \%$ of the dosing interval. Comparative trials indicated that some beta-lactams could achieve bacteriologic eradication of acute otitis media, although major differences in outcome exist among agents based on pathogen, beta-lactamase status, and MIC values. ${ }^{77}$

\section{Pneumococcal Vaccines}

Current concerns about the epidemiology and pathogenesis of pneumococci include changing patterns of virulence, antimicrobial susceptibility, and the increased opportunity for spread in communal settings such as daycare centers. The global perspective of communicable diseases has been reflected in the spread of antibiotic-resistant pneumococci across borders and onto all continents. The widespread, indiscriminate overuse of antibiotics has created a situation that has led to the emergence of $S$. pneumoniae strains that harbor resistance to multiple antibiotics. Despite the continuing development of new antibiotics, the ability to effectively treat pneumococcal diseases is impaired by the rapid worldwide spread of antibiotic-resistant forms of the pathogen.

As a component of public health policies, vaccines are the most cost-effective medical intervention for preventing death and disease. Childhood immunization with vaccines represents the gateway to the provision of comprehensive healthcare which all children should be entitled. ${ }^{82,83}$ This is especially important in developing countries, where more than $80 \%$ of the children up to one year of age could be vaccinated against six childhood diseases (UNICEF).

\section{Development of Pneumococcal Vaccines}

The history of the development of pneumococcal vaccines began early in the 20th century. However, the development of a vaccine with adequate coverage was complicated by the existence of at least 90 distinct serotypes. ${ }^{24}$ This obstacle was overcome with the introduction of a polyvalent vaccine through the persistent efforts of Dr. Robert Austrian. In 1977, a vaccine containing 14 of the most prevalent serotypes was licensed; this polysaccharide vaccine provided coverage against $80 \%$ of invasive pneumococcal isolates in the USA. In 1983, nine other serotypes were added (totaling 23 serotypes), increasing the total coverage to more than $90 \%$ of isolates in developed countries. ${ }^{84}$

For more than 20 years, the pneumococcal 23valent polysaccharide (23PS) vaccine has been available for use in persons older than two years of age. Retrospective studies have firmly established its clinical effectiveness in preventing IPD in older adults. ${ }^{85}$ Moreover, the cost-effectiveness of vaccination against S. pneumoniae has been demonstrated in the USA and for several countries in Western Europe. In preventing nonbacteremic pneumococcal pneumonia in older adults, prospective clinical trials have been inconclusive. However, a recent retrospective study has shown that vaccination with 23PS reduces rates of hospitalization for pneumonia and for all-cause mortality in persons with chronic lung disease. . $^{12,86}$

Although the benefits of 23PS are undeniable, it has several limitations. ${ }^{87}$ Several case-control studies and serotype prevalence evaluations have suggested an overall efficacy for $23 \mathrm{PS}$ of $50 \%$ to $81 \%$ for vaccinespecific serotypes in adults with bacteremic disease. ${ }^{88-}$ 
${ }^{91}$ A major limitation associated with 23PS is that these vaccines are not immunogenic or protective in children younger than two years-the age group at highest incidence for IPD, in part because they elicit a T-cell-independent response. ${ }^{92}$ Similarly in the elderly, antibody levels to important serotypes for this age group decline to prevaccination values within 3 to 7 years. ${ }^{93}$

To overcome the limitations of 23PS, pneumococcal conjugate vaccines were developed. This approach immunizes infants and young children against pneumococcal infections caused by presenting the capsular antigens to their immune systems in a form that is more immunogenic. Using this method, weak or nonimmunogenic antigens can become immunogenic by covalently coupling them to an immunogenic carrier protein. In this way, the antigen acquires the immunogenic character of its carrier and now becomes recognized by the immune system as T-cell dependent. Proteins are broken down into peptides that associate with class II major histocompatibility complex molecules on the cell surface, and then are presented to $\mathrm{T}$ cells to stimulate antibody production by B cells. ${ }^{94}$ Such complexes can stimulate a T-helper-cell response, which in turn, generates stronger booster responses upon restimulation. ${ }^{2}$ Conjugation was used to create Hib protein conjugate vaccines and has proven to be successful in controlling invasive Hib disease in vaccinated infants, especially meningitis. In the USA between 1989 and 1997, the use of Hib conjugate vaccines reduced the incidence of invasive Hib disease by more than $99 \%$ in children younger than five years. $.5,96$

The biochemical issues involved in constructing optimal pneumococcal conjugate vaccines have been shown to vary by serotype. Thus, specific formulations have been necessary for certain serotypes to maximize the immune response and to counteract variable exposure to different pneumococcal polysaccharides. ${ }^{2}$ Other important factors that may influence the immunogenicity of conjugate vaccines include: a) the selection of a protein carrier that avoids carrier-mediated suppression of the antibody response; $b$ ) the frequency for immunization; c) the use of adjuvants; and d) the age and immunocompetency of the host. ${ }^{2,97}$

Fortunately, not all serotypes are equally prevalent, so an effective conjugate vaccine needs to contain only those serotypes most commonly associated with pneumococcal disease. ${ }^{98}$ The number of vaccine serotypes is generally limited because each serotype must be individually conjugated to the carrier, and there is concern about limiting the total dose of carrier protein to control carrier-induced tolerance. ${ }^{74,99}$ Other limitations may include the volume of vaccine dose that would be required for administration if more conju- gated 23PS was included and the overall cost of the vaccine.

\section{Serotype Specificity of Conjugate Vaccines}

The effectiveness of potential conjugate vaccine formulations to prevent pneumococcal disease in children depends, in part, on the proportion of infections caused by serotypes included in the vaccines. To optimize the formulation of conjugate vaccines and to evaluate the appropriateness of their use in various geographic areas and age groups, it was necessary first to understand the serogroup-specific epidemiology of $S$. pneumoniae. ${ }^{100}$ Considering the large number of epidemiologic studies about pneumococcal serotype distribution worldwide, Hausdorff and colleagues performed several data analyses designed to reveal which pneumococcal serotypes should be included in conjugate vaccines. ${ }^{101}$ The investigators analyzed more than 70 data sets to compare the serogroups causing IPD with those represented in conjugate formulations. In each geographic region, the results showed that 5 to 8 serogroups composed at least $75 \%$ of pneumococcal isolates in young children and 10 to 11 serogroups composed the same percentage of isolates in older children or adults. Serogroups in the 7-valent formulation (i.e., $4,6,9,14,18,19$, and 23 ) caused $70 \%$ to $88 \%$ of IPD in young children in the USA, Canada, Oceania, Africa, and Europe, and over $65 \%$ of IPD in Latin America and Asia. Serogroups in the 9-valent formulation (the 7valent vaccine plus serogroups 1 and 5) caused $80 \%$ to $90 \%$ of IPD in each region except Asia (66\%). Serogroup 1 accounted for more than $6 \%$ of IPD in each region, including Europe, but not in the USA, Canada, and Oceania. In contrast, several serogroups not found in the 7-valent, 9-valent, or 11-valent conjugate (the 7valent vaccine plus serogroups $1,3,5$, and 7 ) formulations caused significant disease in older children and adults. Nevertheless, each conjugate formulation could prevent a substantial burden of IPD in each region and age group.

To assess whether certain serogroups of S. pneumoniae were preferentially associated with specific disease manifestations, Hausdorff and associates also analyzed pneumococcal disease studies and assessed the relative frequency of isolation of each serogroup by clinical site (as a proxy for different disease states). ${ }^{101}$ In all age groups, serogroups 1 and 14 were more often isolated from blood, and serogroups 6, 10, and 23 were more often isolated from cerebrospinal fluid. In young children, serogroups 3,19 , and 23 were more often isolated from middle ear fluid. Serogroups represented in conjugate vaccines were isolated slightly 
less frequently from cerebrospinal fluid than from blood or middle ear fluid. Nonetheless, serogroups in the 9-valent conjugate vaccine formulation still composed approximately $75 \%$ of pneumococcal isolates from the cerebrospinal fluid of young children in Europe, the USA, and Canada. These analyses indicate that pneumococcal conjugate vaccines could potentially prevent a substantial proportion of episodes of bacteremic disease, pneumonia, meningitis, and otitis media, especially in young children. ${ }^{101}$ As shown in Table I, several different sets of efficacy trials are in progress worldwide, each examining different clinical endpoints.

\section{Safety and Immunogenicity of Pneumo- coccal Conjugate Vaccines}

One of the first clinical trials with a pneumococcal 7valent conjugate vaccine was performed by Anderson and associates. ${ }^{102}$ This study evaluated the safety, immunogenicity, and immunologic memory of a pneumococcal 7-valent $(4,6 \mathrm{~B}, 9 \mathrm{~V}, 14,18 \mathrm{C}, 19 \mathrm{~F}$, and $23 \mathrm{~F})$ vaccine conjugated to the outer membrane protein complex of Neisseria meningitidis (Pnc-OMP) in young infants. Healthy two-month-old infants and 12- to 15month-old control infants were recruited from participating private practices. Infants $(n=25)$ were vaccinated at two, four, and six months of age with PncOMP, followed by a single dose of 23PS $(n=20)$ at 12 to 15 months of age. Thirteen infants who had not received Pnc-OMP served as control subjects and were given a single dose of 23PS at 12 to 15 months of age.

Pnc-OMP was well tolerated by the infants. The conjugate vaccine was highly immunogenic in young infants, significantly increasing antibody to all seven serotypes after two or three injections. At 12 to 15 months of age, infants who had been primed with the conjugate vaccine had a brisk immunologic response to the booster injection of 23PS. Control infants had negligible immunologic responses to 4 of the 7 serotypes and low responses to the other three serotypes. Overall, Pnc-OMP administered to young infants was well tolerated highly immunogenic and provided immunologic memory to an injection of 23PS.

In 1997, Dagan and colleagues published a report detailing the safety and immunogenicity of two 4valent pneumococcal vaccines containing serotypes 6B, 14, 19F, and 23F. ${ }^{103}$ These polysaccharides were conjugated to either a tetanus toxoid (Pnc-T) or a diphtheria toxoid (Pnc-D). Pnc-T, Pnc-D, or placebo vaccines were administered intramuscularly in a double-blind fashion (25 infants per group) at two, four, and six months of age. At 12 months of age, all 75 children were boosted with 23PS. Both Pnc-T and Pnc-D vaccines resulted in higher antibody concentrations compared with placebo after primary immunity (serotype 6B: $1.66,1.40$, and $0.60 \mu \mathrm{g} / \mathrm{ml}$; serotype $14: 4.81,2.65$, and $2.22 \mu \mathrm{g} / \mathrm{ml}$; serotype $19 \mathrm{~F}: 2.40,3.48$, and $0.83 \mu \mathrm{g} /$ $\mathrm{ml}$; and serotype 23F: $0.96,0.44$, and $0.35 \mu \mathrm{g} / \mathrm{ml}$, respectively). The proportion of infants with antibody concentrations above $1.0 \mu \mathrm{g} / \mathrm{ml}$ was also higher in the conjugate vaccine groups than in the placebo group. After the booster with 23PS, both the geometric antibody concentrations and the proportion of infants with concentrations $1.0 \mu \mathrm{g} / \mathrm{ml}$ or greater were significantly higher in the Pnc-T or Pnc-D groups than in the placebo group. Both 4-valent conjugate vaccines were well tolerated, and each induced serotype-specific anticapsular antibodies and immunologic memory.

Table I

Pneumococcal Conjugate Vaccines in Development

\begin{tabular}{|c|c|c|c|}
\hline Vaccine conjugate & Serotypes contained & Manufacturer & Status \\
\hline 9 polysaccharides conjugated to $\mathrm{CRM}_{197}$ (PN CRM9) & $1,4,5,6 \mathrm{~B}, 9 \mathrm{~V}, 14,18 \mathrm{C}, 19 \mathrm{~F}$, and $23 \mathrm{~F}$ & W yeth Lederle Vaccines & Phase III \\
\hline 11 polysaccharides conjugated to $\mathrm{CRM}_{197}$ (PN CRM11) & $1,3,4,5,6 \mathrm{~B}, 7 \mathrm{~F}, 9 \mathrm{~V}, 14,18 \mathrm{C}, 19 \mathrm{~F}$, and $23 \mathrm{~F}$ & W yeth Lederle Vaccines & Preclinica \\
\hline $\begin{array}{l}7 \text { polysaccharides conjugated to } \\
\text { Neisseria meningitidis Group B (Pnc-O MP) }\end{array}$ & $4,6 \mathrm{~B}, 9 \mathrm{~V}, 14,18 \mathrm{C}, 19 \mathrm{~F}$, and $23 \mathrm{~F}$ & Merck \& Co. & Phase II \\
\hline $\begin{array}{l}4 \text { polysaccharides conjugated to diphtheria toxoid (Pnc-D) } \\
\text { or tetanus toxoid (Pnc-T) }\end{array}$ & $6 \mathrm{~B}, 14,19 \mathrm{~F}$, and $23 \mathrm{~F}$ & Aventis & Phase II \\
\hline $\begin{array}{l}9 \text { polysaccharides conjugated to diphtheria toxoid } \\
\text { or tetanus toxoid }\end{array}$ & $1,4,5,6 \mathrm{~B}, 9 \mathrm{~V}, 14,18 \mathrm{C}, 19 \mathrm{~F}$, and $23 \mathrm{~F}$ & Aventis & Phase II \\
\hline 9 polysaccharides conjugated to a protein carrier & $1,4,5,6 \mathrm{~B}, 9 \mathrm{~V}, 14,18 \mathrm{C}, 19 \mathrm{~F}$, and $23 \mathrm{~F}$ & SmithK line Beecham & Phase II \\
\hline
\end{tabular}


The impact of a conjugate vaccine on pneumococcal carriage was studied by Mbelle and colleagues. ${ }^{104}$ The study evaluated the safety, immunogenicity, and impact on carriage of a pneumococcal 9-valent (serotypes $1,4,5,6 \mathrm{~B}, 9 \mathrm{~V}, 14,18 \mathrm{C}, 19 \mathrm{~F}$, and $23 \mathrm{~F}$ ) conjugate vaccine (PNCRM9). The 9-valent vaccine was administered at ages 6,10 , and 14 weeks in a double- blind, randomized, placebo-controlled trial in 500 infants in Soweto, South Africa. No serious local or systemic adverse events were recorded. Significant antibody responses to all pneumococcal serotypes were observed four weeks after the third dose. Hib polyribosylribitol phosphate geometric mean concentration (GMC) (11.62 $\mu \mathrm{g} / \mathrm{ml})$ and diphtheria antibodies $(1.39 \mathrm{IU} / \mathrm{ml})$ were significantly higher in children receiving PNCRM9 compared with placebo recipients $(4.58 \mu \mathrm{g} / \mathrm{ml}$ and 0.98 $\mathrm{IU} / \mathrm{ml}$, respectively). Nasopharyngeal carriage of the vaccine-specific serotypes at 9 months of age decreased in the group receiving PNCRM9 compared with the placebo group (18\% vs 36\%). However, carriage of nonvaccine-specific serotypes was found to be more prevalent (36\% vs $25 \%$ ), suggesting the potential for nasopharyngeal replacement by serotypes not included in the vaccine. Carriage of penicillin-resistant pneumococci $(21 \%$ vs $41 \%)$ and cotrimoxazole-resistant pneumococci $(23 \%$ vs $35 \%)$ were significantly reduced nine months after vaccination with PNCRM9, compared with controls.

Safety, tolerability, and immunogenicity studies have demonstrated an adequate immune response that is serotype-specific. Rennels and colleagues determined the safety and immunogenicity of PNCRM7 administered at two, four, six, and 12 to 15 months of age. ${ }^{105}$ PNCRM7 comprises serotypes $4,6 \mathrm{~B}, 9 \mathrm{~V}, 14,18 \mathrm{C}$, $19 \mathrm{~F}$, and $23 \mathrm{~F}$, and is covalently linked to a nontoxic variant of diphtheria $\left(\mathrm{CRM}_{197}\right)$. Two-month-old infants $(n=212)$ were equally randomized to receive four consecutive doses of PNCRM7 or meningococcal group C conjugate vaccine (control). Concomitantly administered routine vaccines were oral polio vaccine and combined diphtheria toxoid, tetanus toxoid, and whole-cell pertussis vaccine (DTP)/Hib conjugate vaccine $(\mathrm{HbOC})$ at two, four, and six months, and either measles-mumps-rubella vaccine or $\mathrm{HbOC}$ at 12 to 15 months. Active safety surveillance was conducted for 3 days after each dose. Antibody concentrations to each of the 7-pneumococcal serotypes were measured by enzyme-linked immunosorbent assay prevaccination after Doses 2 and 3, prebooster, and postbooster.

Significantly fewer children experienced local reactions at the PNCRM7 injection site than at the DTP/ $\mathrm{HbOC}$ site. There was no increase in the incidence or severity of local reactions at the PNCRM7 site with increasing doses of the vaccine. Mild-to-moderate postvaccination fever was common in both the PNCRM7 and control vaccine groups, which may have been related to the concurrently administered DTP/HbOC. All seven vaccine serotypes were immunogenic and kinetics of the immune responses was serotype-specific. After three doses of PNCRM7, 92\% to $100 \%$ of children had an antibody of $0.15 \mu \mathrm{g} / \mathrm{ml}$ or greater, and $51 \%$ to $90 \%$ achieved a level of $1 \mu \mathrm{g} / \mathrm{ml}$ or greater against specific serotypes. A booster dose of PNCRM7 resulted in a brisk anamnestic response to all seven vaccine serotypes, demonstrating effective stimulation of T-cell memory by the primary series of vaccinations. Primary immunization followed by a booster dose of PNCRM7 was acceptably safe and resulted in significant rises in antibody to all seven serotypes.

Shinefield and colleagues performed a randomized, double-blind safety and immunogenicity study in 302 healthy infants in the Northern California Kaiser Permanente Health Plan, in which infants received either PNCRM7 or meningococcal group $C$ conjugate vaccine (control) at two, four, and six months of age and a booster at 12 to 15 months. ${ }^{106}$ The primary objectives of the study were to: a) determine the safety and immunogenicity of PNCRM7 in infants, and b) examine the effects of concurrent hepatitis $B$ immunization during the primary series and the effects of concurrent diphtheria and tetanus toxoid and acellular pertussis (DTaP [ACEL-IMUNE"]) and HbOC (HibTITER") immunization - at the time of the booster dose- on the safety and immunogenicity of PNCRM7. Antibody titers were determined on blood samples drawn before and one month after the primary series and the booster dose.

After the third dose of PNCRM7, GMC ranged from $1.01 \mu \mathrm{g} / \mathrm{ml}$ for serotype $9 \mathrm{~V}$ to $3.72 \mu \mathrm{g} / \mathrm{ml}$ for serotype 14 . More than $90 \%$ of all subjects had a Postdose 3 titer of $0.15 \mu \mathrm{g} / \mathrm{ml}$ or greater for all serotypes, and the percentage of infants with a Postdose 3 titer of $1.0 \mu \mathrm{g} /$ $\mathrm{ml}$ or greater ranged from $51 \%$ for serotype $9 \mathrm{~V}$ to $89 \%$ for serotype 14. After the PNCRM7 booster dose, the GMC of all seven serotypes increased significantly over both Postdose 3 and Predose 4 antibody levels. In the primary series, there were no significant differences in the GMC of pneumococcal antibodies between the subjects given PNCRM7 alone or concurrently with hepatitis B vaccine. At the toddler dose, concurrent administration of PNCRM7 and DTaP/HbOC resulted in a near conventional threshold for statistical significance of a Postdose 4 GMC for serotype 23F (alone vs concurrent, $6.75 \mu \mathrm{g} / \mathrm{ml}$ vs $4.11 \mu \mathrm{g} / \mathrm{ml} ; p=0.057$ ), as well as significantly lower antibody GMC for $H$. influenzae polyribosylribitol phosphate, diphtheria toxoid, per- 
tussis toxin, and filamentous hemagglutinin. When PNCRM7 was administered concurrently at the booster dose with $\mathrm{DTaP} / \mathrm{HbOC}$ vaccines, lower antibody titers were noted for some of the antigens, compared with the antibody response when PNCRM7 was given separately. Because the GMC of the booster responses were all generally high, and all subjects achieved similar percentages above predefined antibody titers, these differences were probably not clinically significant.

\section{Efficacy of PNCRM7 Against IPD and A cute Otitis Media}

Black and Shinefield reported the results from a study conducted by the Northern California Kaiser Permanente Vaccine Study Center to determine the efficacy, safety, and immunogenicity of PNCRM7 and its effectiveness against invasive disease caused by the serotypes contained in the vaccine. ${ }^{107}$ A secondary endpoint was to determine efficacy against clinical episodes of otitis media. The conjugate vaccine was administered to infants at two, four, and six months of age, followed by a booster dose at 12 to 15 months of age in a double-blind trial; 37868 children were randomly assigned 1:1 to receive either PNCRM7 or meningococcus type $\mathrm{C} \mathrm{CRM}_{197}$ conjugate vaccine (control). The primary study outcome was IPD caused by vaccine-specific serotypes. Other outcomes included: a) overall impact on IPD, regardless of serotype; $b$ ) effectiveness against clinical otitis media visits and episodes; c) impact against frequent and severe otitis media; and d) ventilatory tube placement. In addition, the serotype-specific efficacy against otitis media was estimated in an analysis of spontaneously draining ears.

Through August 1998, no cases of pneumococcal infection due to vaccine serotype pneumococci had occurred in those children receiving PNCRM7. There were 17 cases of IPD caused by vaccine serotypes in fully vaccinated children and five among partially vaccinated cases in the control group, for a vaccine efficacy of $100 \%$. Blinded case ascertainment was continued until April 1999. At that time, 40 cases of IPD in fully vaccinated children caused by vaccine-specific serotypes had been identified, all but one in the control group, for an efficacy of $97.4 \%$ (95\% confidence interval, $82.7 \%-99.9 \%$ ); and 52 cases in the intent-to-treat analysis, all but three were in the control group for an efficacy of $93.9 \%$ (95\% confidence interval, $79.6 \%$ $98.5 \%$ ). There was no evidence of any increase of disease caused by nonvaccine serotypes. These results indicated that PNCRM7 was safe and highly effective in preventing IPD caused by the seven serotypes contained in the vaccine. In February 2000 after extensive research, PNCRM7 (Prevenar $^{\circledR} /$ Prevnar $^{\circledR}$ ) was licensed for use in the USA for the prevention of IPD in infants and young children caused by S. pneumoniae.

The efficacy of PNCRM7 in preventing acute otitis media had been documented in the Kaiser Permanente trial as well as the Finnish Otitis Media trial (FinOM). ${ }^{103}$ Efficacy estimates of PNCRM7 from both trials were remarkably similar; efficacy rates were higher in recurring infection (Table II). ${ }^{107}$ Overall efficacy of the conjugate vaccine against all episodes of acute otitis media regardless of etiology was approximately $6 \%$ in both studies. In the FinOM Trial, efficacy against acute otitis media caused by vaccine-specific serotypes was $57 \%$; efficacy against various vaccine serotypes ranged from $25 \%$ to $84 \%$. Efficacy against cross-reactive serotypes was $51 \%$. Although PNCRM7 reduced the rate of acute otitis media due to vaccine-specific serotypes and cross-reactive types, there was some associated replacement occurring with nonvaccine serogroups. An increased of 33\% was observed in the rate of acute otitis media caused by such nonvaccine serotypes; these serotypes not included in the vaccine have the potential to be pathogenic as well. ${ }^{108}$

In the Kaiser Permanente trial there was no evidence of increased disease due to nonvaccine serotypes. Efficacy in this trial against physician office visits, episodes of acute otitis media, instances of frequent otitis media, and related ventilatory tube placement was $8.9 \%, 7.0 \%, 9.3 \%$, and $20.1 \%$, respectively ( $p<0.04$ for all). In the analysis of spontaneously draining ears, serotype-specific effectiveness was $66.7 \%$. Overall, the results of these two trials have demonstrated that $\mathrm{PN}$ CRM7 had an impact on reducing otitis media episodes and providing protection against both vaccine-specific and cross-reactive pneumococcal serotypes.

\section{Table II \\ Efficacy of PNCRM7 Against Acute Otitis Media (AOM)}

\begin{tabular}{lcc}
\multirow{2}{*}{ Definition of AOM } & \multicolumn{2}{c}{ Vaccine Efficacy $(95 \% \mathrm{Cl})$} \\
\cline { 2 - 3 } All episodes of AOM & FinOM trial & NCKP trial \\
\hline All confirmed episodes & $6 \%(-4-15)$ & $5.8 \%(3.7-7.8)$ \\
\hline Episodes of pneumococcal AOM & $3 \%(-5-17)$ & - \\
\hline AO M due to vaccine-specific serotypes & $57 \%(44-45)$ & - \\
\hline Frequently recurring AO M & $16 \%(-6-35)$ & $9.5 \%(3.2-15.3)$
\end{tabular}

FinO M: Finnish O titis Media; N CKP: N orthern California Kaiser Permanente 


\section{Recommendations for the Prevention of IPD}

The American Academy of Pediatrics ${ }^{109}$ and the Centers for Disease Control (CDC) Advisory Committee on Immunization Practices (ACIP) ${ }^{110}$ have published their recommendations for the prevention of pneumococcal infections, including the use of pneumococcal conjugate and polysaccharide vaccines and antibiotic prophylaxis. PNCRM7 is recommended for universal use in children 23 months and younger, and should be administered concurrently with other recommended childhood vaccines at two, four, six, and 12 to 15 months of age. As shown in Table III, administration of a reduced number of doses is recommended for children 7 to 23 months old who have not received previous doses of PNCRM7. Two doses of PNCRM7 are recommended for children 24 to 59 months old at high risk of IPD -including children with functional, anatomic, or congenital asplenia; infection with human immunodeficiency virus; and other predisposing conditions- who have not been immunized previously with PNCRM7 (Table IV).

Recommendations have been made for the use of 23PS in high-risk children to expand serotype coverage. High-risk children should be given vaccines at the earliest possible opportunity. The use of antibiotic prophylaxis in children younger than five years of age with functional or anatomic asplenia, including children with sickle cell disease, continues to be recommended. Children who have not experienced IPD and who have received the recommended pneumococcal immunizations may discontinue prophylaxis after five years of age. The safety and efficacy of PNCRM7 and 23PS in children 24 months or older at moderate or low risk of invasive pneumococcal infection remains under investigation. Current FDA indications are for the administration of PNCRM7 to children younger than 24 months. Data are insufficient to recommend

\section{Table III \\ Recommended Schedule of Doses for PNCRM7 in Previously Unvaccinated Children* (Primary Series and Catch-up Immunizations)}

\begin{tabular}{|c|c|c|}
\hline Age at first dose & Primary series & Booster dose $e^{\ddagger}$ \\
\hline 2-6 months & 3 doses, 6-8 weeks apart & 1 dose at $12-15$ months of age \\
\hline 7-11 months & 2 doses, 6- 8 weeks apart & 1 dose at $12-15$ months of age \\
\hline $12-23$ months & 2 doses, 6 - 8 weeks apart & \\
\hline$\geq 24$ months & 1 dose & \\
\hline
\end{tabular}

Table IV

American Academy of Pediatrics* Recommendations for Immunization with PNCRM7 or 23PS for Children at High Risk ${ }^{\ddagger}$ of Invasive Pneumococcal Disease

\begin{tabular}{|c|c|c|}
\hline Age & Previous doses & Recommendations \\
\hline$\leq 23$ months & None & See Table III \\
\hline 24-59 months & 4 doses of PN CRM 7 & $\begin{array}{l}1 \text { dose of 23PS at } 24 \text { months, at least } 6-8 \text { weeks after last dose of PN CRM7 } \\
1 \text { dose of 23PS, 3-5 years after the first dose of 23PS }\end{array}$ \\
\hline 24-59 months & $1-3$ doses of PN CRM 7 & $\begin{array}{l}1 \text { dose of PN CRM } 7 \\
1 \text { dose of 23PS, } 6-8 \text { weeks after the last dose of PN CRM } 7 \\
1 \text { dose of 23PS, 3-5 years after the first dose of 23PS }\end{array}$ \\
\hline 24-59 months & 1 dose of 23PS & $\begin{array}{l}2 \text { doses of PN CRM 7, } 6-8 \text { weeks apart, beginning at least } 6-8 \text { weeks after last dose of 23PS } \\
1 \text { dose of 23PS, 3-5 years after the first dose of 23PS }\end{array}$ \\
\hline 24-59 months & None & $\begin{array}{l}2 \text { doses of PN CRM 7, 6-8 weeks apart } \\
1 \text { dose of 23PS, } 6-8 \text { weeks after the last dose of PN CRM } 7 \\
1 \text { dose of 23PS, 3-5 years after the first dose of 23PS }\end{array}$ \\
\hline \multicolumn{3}{|c|}{$\begin{array}{l}\text { * The recommendations in this statement do not indicate an exclusive course of treatment or serve as a standard of medical care.Variations, taking into } \\
\text { account individual circumstances, may be appropriate. Copyright } \odot 2000 \text { by the American Academy of Pediatrics. No part of this statement may be } \\
\text { reproduced in any form or by any means without prior written permission from the American Academy of Pediatrics except for one copy for personal } \\
\text { use }\end{array}$} \\
\hline
\end{tabular}


routine administration of PNCRM7 for children at moderate risk of IPD, including all children 24 to 35 months old, children 36 to 59 months old who attend out-of-home care, and children 36 to 59 months old who are of Native American, Alaska Native, or African American descent. However, all children 24 to 59 months old, regardless of whether they are at low or moderate risk, may benefit from the administration of pneumococcal immunizations. Therefore, a single dose of PNCRM7 or 23PS vaccine may be given to children 24 months or older. 23PS is an acceptable alternative to PNCRM7, although an enhanced immune response and probable reduction of nasopharyngeal carriage favor the use of PNCRM7, whenever possible.

\section{Economic Impact of Vaccination A gainst Pneumococcal Disease}

To evaluate the projected health and economic impact of pneumococcal conjugate vaccination of healthy US infants and young children, Lieu and associates designed a cost-effectiveness analysis based on data from the Northern California Kaiser Permanente randomized trial and other published and unpublished sources. The study used a hypothetical US birth cohort of 3.8 million infants. ${ }^{111}$ The investigators studied hypothetical comparisons of routine vaccination of healthy infants requiring four doses of PNCRM7 (at two, four, six, and 12-15 months), catch-up vaccination of children 2 to 4.9 years of age requiring one dose, and children receiving no intervention. Study objectives were the determination of cost per life-year saved and cost per episode of meningitis, bacteremia, pneumonia, and otitis media prevented.

Results from the study showed that vaccination of healthy infants would prevent more than 12000 cases of meningitis and bacteremia, 53000 cases of pneumonia, one million episodes of otitis media, and 116 deaths due to pneumococcal infection. Before accounting for vaccine costs, the vaccination program would save $\$ 342$ million in medical costs and $\$ 415$ million in work-loss and other costs from averted pneumococcal disease. Vaccination of healthy infants would result in a net savings for society if the vaccine cost less than $\$ 46$ per dose, and savings for the health care payer if the vaccine cost less than $\$ 18$ per dose. At the manufacturer's list price of $\$ 58$ per dose, infant pneumococcal conjugate vaccination would cost $\$ 80000$ per life-year saved, compared with the accepted benchmark of $\$ 50000$ per life-year saved (other estimated costs would be $\$ 160$ per otitis media episode prevented, \$3 200 per pneumonia case prevented, $\$ 15000$ per bacteremia case prevented, and $\$ 28000$ per meningitis case prevented). The cost-effectiveness of an additional program to administer one dose of vaccine to children 2 to 4.9 years of age would vary, depending on the children's ages, relative risks of pneumococcal disease, and vaccine cost.

Another analysis of benefits and costs of routine vaccination with PNCRM7 was performed by Weycker and colleagues. ${ }^{112}$ A decision-analytic model was created to estimate the cumulative numbers of cases and costs to age 10 years for acute otitis media, tympanostomy and related procedures (TRP), and CAP in children who either did or did not receive PNCRM7. Seven hypothetical cohorts of 1000 children, stratified by age at initial vaccination, were followed. Outcome measures included cost of vaccination, cumulative numbers of cases of acute otitis media, TRP and CAP to age 10 years, and related disease costs, including medical treatment and parental work-loss. Routine vaccination of 1000 children against pneumococcal infection would cost between \$57 000 and \$226000 depending on age. Acute otitis media, TRP and CAP to age 10 years would decline by 139 cases to 330 , by 8 cases to 22 , and by 15 cases to 30 , respectively; costs of medical treatment and work-loss would correspondingly decline by $\$ 56000$ to $\$ 138000$. Expected net economic benefits (benefits minus costs) of vaccination against pneumococcal otitis media and pneumonia range from $-\$ 88000$ to $\$ 15000$ for children younger than two years of age, and from $-\$ 1000$ to $\$ 31000$ for those 2 to 5 years of age at vaccination. Results showed that routine vaccination for children younger than two years of age appears to be cost increasing, but would be cost-saving for children 2 to 5 years of age who would require only a single dose of the vaccine.

There is little information at present, however, on the duration of protection afforded by pediatric bacterial vaccines. It is known that pneumococcal disease decreases after five years of age. The study by Weycker and associates assumed that immunity would extend to age 10 years for children younger than two years of age at initial vaccination, but at half the initial rate after five years of age. Long-term studies and clinical usage data are needed to accurately estimate the persistence of pneumococcal conjugate vaccines protection.

Vaccination of healthy US infants with PNCRM7 has the potential of being cost-effective. The financial costs of medical use and work-loss resulting from common vaccine-associated symptoms are significant, and should be incorporated into economic analyses. ${ }^{113}$ In addition to measurable but highly significant costs, the vaccine should be appraised based on the less tangi- 
ble value of preventing mortality and morbidity from pneumococcal disease.

\section{Future Challenges and Considerations}

Conjugate vaccines have reduced the incidence of invasive disease caused by Hib in industrialized countries and may be highly effective against $S$. pneumoniae. However, the serotype specificity of pneumococcal conjugate vaccines has led to the concern that their use may increase carriage of and disease from serotypes not included in the vaccines. Replacement has not occurred with Hib conjugate vaccines, but has been reported in trials of pneumococcal conjugate vaccines. In the controlled trial done in Soweto, South Africa by Mbelle and associates, results showed that vaccination with a 9-valent pneumococcal vaccine significantly reduced nasopharyngeal carriage of serotypes $19 \mathrm{~F}$ and 6B. ${ }^{104}$ Serotypes $6 \mathrm{~A}$ and $6 \mathrm{~B}$ differ only in the linkage of a single sugar in the carbohydrate molecule, and it is of some concern that the vaccine did not reduce carriage of serotype $6 \mathrm{~A} \cdot{ }^{114}$ Fifteen percent of the residual nasopharyngeal carriage of antibiotic-resistant strains in the study was due to the continued carriage of serotype 6A. These results would seem to correlate with those of Nahm and colleagues, who found that polysaccharide from serotype 6B induced cross-reacting antibodies that had little opsonic activity against serotype 6A. ${ }^{115}$ It may, therefore, be important for future generations of vaccines to include this pneumococcal serotype. The concept that widespread use of pneumococcal conjugate vaccines might lead to recolonization by nonvaccine serotypes, alteration of serotype distribution, and new strains of invasive disease remains controversial. Nasopharyngeal studies using various pneumococcal conjugate vaccines have reported wide variability in the degrees of carriage replacement; however, these studies have not linked such carriage replacement to clinical disease. ${ }^{116,117}$

In order to overcome serotype specificity of pneumococcal vaccines, extensive work has been done by Briles and associates regarding pneumococcal proteins and the potential for use as pneumococcal vaccines. ${ }^{118}$ Pneumococcal proteins either alone, in combination with each other, or in combination with capsular polysaccharide-protein conjugates may be useful vaccine components. Four proteins with the potential for use in vaccines are PspA, PspC, pneumolysin, and PsaA. In a mouse model of carriage, PsaA and PspC were the most efficacious vaccine proteins. Of these proteins, PsaA was the best at eliciting protection against carriage. However, a combination of PspA and pneumolysin may elicit a stronger immunity to pul- monary infection and possibly sepsis than either protein alone. Results of a phase I trial of a recombinant family 1 PspA demonstrated that the protein was immunogenic and safe. Injection of $0.1 \mathrm{ml}$ of immune serum diluted $1 / 400$ protected mice from a fatal infection with S. pneumoniae. Under these conditions, preimmune serum was not protective. The immune human serum protected mice from infections with pneumococci expressing either of the major PspA families (1 and 2) and both of the pneumococcal capsular types tested ( 3 and 6$).{ }^{119}$

The possibility of using immunity to virulence proteins of S. pneumoniae to elicit immunity against pneumococci has been examined. Additionally, PspA had been found to have efficacy against otitis media in animals. Vaccination with a mixture of PsaA and PspA had been observed to offer better protection against nasal carriage in mice than vaccination with either protein alone. PspA and pneumolysin have been shown to elicit protection against invasive pneumococcal infections. The inclusion of some of these proteins into the polysaccharide-protein conjugate vaccines may enhance their efficacy against otitis media and may help to constitute a successful all-protein pneumococcal vaccine. ${ }^{120}$ Mathematical models can be used to elucidate the contrasting outcomes, predict the conditions under which serotype replacement is likely, interpret the results of conjugate vaccine trials, design trials that will better detect serotype replacement (if it occurs), and suggest factors to consider in choosing the serotype composition of vaccines. ${ }^{121}$

PNCRM7 has been shown to be highly effective for children younger than two years. No significant safety problems associated with vaccination have occurred in clinical trials conducted since $1992 .{ }^{122}$ Clinical trials show that PNCRM7 is more than $95 \%$ effective at preventing IPD due to serotypes included in the vaccine and has also shown some efficacy against noninvasive disease. ${ }^{107}$ The ability of PNCRM7 to prevent IPD may also present an opportunity to reduce empiric use of antibiotics for young children who have fever of unknown origin. Concern about IPD among young children who present with fever of unknown origin is a common reason for antibiotic prescription in this age group. The importance of such empiric therapy has been questioned in the USA now that the incidence of invasive disease caused by Hib has declined dramatically. ${ }^{123}$ Empiric therapy may be even less well founded among children who also received appropriate vaccination with PNCRM7. Thus, antibiotic use in this age group may be reduced in settings with high vaccination coverage. ${ }^{124}$ 
Future hopes of reducing childhood mortality by vaccination against pneumococcal infections do not lie solely in the vaccine formulations mentioned herein. Natural populations of pneumococci may switch their capsular genes, and the selective pressure of conjugate vaccination may lead to the spread of resistance genes to strains with nonvaccine-associated capsules. ${ }^{125}$ As the capsule is the major virulence determinant of the pneumococcus, it is probable that the nonvaccine serotypes will remain less invasive.

Although global use of pneumococcal conjugate vaccines may reduce the high rates of childhood mortality in developing countries, the geographic and temporal variation of $S$. pneumoniae isolated from children and the capsular switching events already demonstrated in a Mexican invasive strain suggest that species-wide, protein-based vaccines may be needed to provide more widespread protection against death and disease caused by the bacterial pathogen..$^{50}$ Additionally, the concerted efforts of public health authorities, pediatricians, and community members toward a more prudent use of antibiotics could enable better control and improve the outcomes of infections caused by S. pneumoniae and other bacterial infectious agents.

\section{Summary}

As one of the leading causes of bacteremia, meningitis, pneumonia, and otitis media in the pediatric population, S. pneumoniae represents a significant public health burden worldwide. Treatment and management of pneumococcal disease has become increasingly complex because of the growing incidence of antibiotic-resistant strains of S. pneumoniae; thus, the best management strategy may be prevention of the disease through vaccination. Although several pneumococcal vaccines have been studied in infants and children, only PNCRM7 is currently approved in the USA for the prevention of IPD in infants and young children. Vaccination with PNCRM7 is safe and effective in infants and young children, and routine vaccination may promote the significant improvement of outcomes for patients with pneumococcal disease.

The routine use of PNCRM7 could improve patient outcomes by safeguarding against the development of antibiotic-resistant strains of pneumococcus, thus simplifying the management of pneumococcal disease. Additionally, the costs associated with treatment could be substantially reduced. The cost of pneumococcal conjugate vaccines may determine the ability of the global community to use these vaccines, particularly in developing countries where limited healthcare budgets may dictate that funds be used for more pressing priorities. ${ }^{126}$ However, in light of the global importance of $S$. pneumoniae as a cause of illness, sequelae, and death, and the emergence of drug resistance, which is making these infections more difficult to treat successfully, it is time a concerted effort be applied using scientific advances to overcome obstacles of critical clinical and public health importance. ${ }^{127}$

\section{Acknowledgments}

We are grateful to Kenneth Glinka for his careful review of the manuscript and helpful comments.

\section{References}

1. Dagan R, Fraser D, G reif Z, Keller N, Kaufstein M, Shazberg G et al. A nationwide prospective surveillance study in Israel to document pediatric invasive infections, with an emphasis on Haemophilus influenzae type $b$ infections. Israeli Pediatric Bacteremia and Meningitis Group. Pediatr Infect D is J 1998; 17(9 Suppl):S198-S203.

2. Klein DL. Pneumococcal disease and the role of conjugate vaccines. Microb Drug Resist 1999; 5:147-157.

3. Austrian R. The enduring pneumococcus: unfinished business and opportunities for the future. Microb Drug Resist 1997; 3(2):111-115.

4. Pneumococcal vaccines:W HO Position Paper.W kly Epidemiol Rec 74, 177-183. 1999.

5. Sniadack D H, Schwartz B, Lipman H, Bogaerts J, Butler JC, D agan R et al. Potential interventions for the prevention of childhood pneumonia: geographic and temporal differences in serotype and serogroup distribution of sterile site pneumococcal isolates from children - implications for vaccine strategies. Pediatr Infect D is J 1995; 14(6):503-510.

6. Shann F. Etiology of severe pneumonia in children in developing countries. Pediatr Infect D is 1986; 5(2):247-252.

7. Centers for Disease Control and Prevention. Prevention of pneumococcal disease: recommendations of the Advisory Committee on Immunization Practices (ACIP). 46, 1-24. 1997.

8. Janoff EN, Rubins JB. Invasive pneumococcal disease in the immunocompromised host. Microb Drug Resist 1997; 3(3):215-232.

9. Rubins JB, PuriAK, Loch J, C harboneau D, MacD onald R, O pstad $N$ et al. Magnitude, duration, quality, and function of pneumococcal vaccine responses in elderly adults.J Infect $D$ is 1998; 178(2):431-440.

10. Ekdahl K, Martensson A, Kamme C. Bacteraemic pneumococcal infections in Southern Sweden 1981-96: trends in incidence, mortality, agedistribution, serogroups and penicillin- resistance. Scand J Infect D is 1998; 30(3):257-262.

11. N ielsen SV, Henrichsen J. Incidence of invasive pneumococcal disease and distribution of capsular types of pneumococci in D enmark, 1989-94. Epidemiol Infect 1996; 117(3):411-416.

12. Kertesz DA, Di Fabio JL, C unto Brandileone MC, C astaneda E, EchánizAvilés $G$, Heitmann I et al. Invasive Streptococcus pneumoniae infection in Latin A merican children: results of the Pan A merican Health 0 rganization Surveillance Study. C lin Infect D is 1998; 26(6):1355-1361.

13. Echániz-Avilés $G, C$ arnalla-Barajas $N$,Velázquez-Meza ME, Soto-N ogueron A, Espinoza-de los Monteros LE, Solórzano-Santos F. Capsular types of Streptococcus pneumoniae causing disease in children from Mexico City. Pediatr Infect D is J 1995; 14(10):907-909. 
14. Echániz-Avilés G, Velázquez-Meza ME, C arnalla-Barajas MN, SotoNogueron A, Solórzano-Santos F, Pérez MA et al. Antimicrobial susceptibilities and capsular types of invasive Streptococcus pneumoniae isolated in children in Mexico City. Microb Drug Resist 1997; 3(2):153-157.

15. Brandileone MC, Vieira VS, Casagrande ST, Zanella RC, Guerra ML, Bokermann $S$ et al. Prevalence of serotypes and antimicrobial resistance of Streptococcus pneumoniae strains isolated from Brazilian children with invasive infections. Pneumococcal Study Group in Brazil for the SIREVA Project. Regional System for Vaccines in Latin America. Microb D rug Resist 1997; 3(2):141-146.

16. Di Fabio JL, HommaA, de Q uadros C. Pan A merican Health 0 rganization epidemiological surveillance network for Streptococcus pneumoniae. Microb D rug Resist 1997; 3(2):131-133.

17. Rossi A, Ruvinsky R, Regueira M, C orso A, Pace J, Gentile A et al. D istribution of capsular types and penicillin-resistance of strains of Streptococcus pneumoniae causing systemic infections in Argentinian children under 5 years of age. Microb D rug Resist 1997; 3(2):135-140.

18. Castañeda E, Leal AL, Castillo O, De La HF,Vela MC, Arango $M$ et al. Distribution of capsular types and antimicrobial susceptibility of invasive isolates of Streptococcus pneumoniae in Colombian children. Pneumococcal Study Group in Colombia. Microb Drug Resist 1997; 3(2):147-152.

19. Hortal M, Ruvinsky R, Rossi A,A gudelo Cl, Castañeda E, Brandileone C et al. Impacto de Streptococcus pneumoniae en las neumonías del niño latinoamericano. Grupo SIREVA-Vigía. 185-195. 1-10-2000. Pan American Health 0 rganization.

20. Griffith F.The significance of pneumococcal types.J Hyg 27, 113-159. 1928.

21.A very OT, MacLeod C M, McC arty M. Studies on the chemical nature of the substance inducing transformation of pneumococcal types. Induction of transformation by a desoxyribonucleic acid fraction isolated from pneumococcus type III. J Exp Med 1944; 79:137-158.

22.W atson DA, Musher DM, Jacobson JW, Verhoef J.A brief history of the pneumococcus in biomedical research: a panoply of scientific discovery. Clin Infect D is 1993; 17(5):913-924.

23.A lonso D eVelasco E,Verheul AF,Verhoef J, Snippe H. Streptococcus pneumoniae: virulence factors, pathogenesis, and vaccines. Microbiol Rev 1995; 59(4):591-603.

24. Henrichsen J. Six newly recognized types of Streptococcus pneumoniae. J Clin Microbiol 1995; 33:2759-2762.

25. Scott JA, Hall AJ, D agan R, D ixon JM, Eykyn SJ, FenollA et al. Serogroupspecific epidemiology of Streptococcus pneumoniae: associations with age, sex, and geography in 7,000 episodes of invasive disease. C lin Infect D is 1996; 22(6):973-981.

26. Leiberman A, D agan R, Leibovitz E, Yagupsky P, Fliss D M.The bacteriology of the naso pharynx in childhood. Int J Pediatr 0 torhinolaryngol 1999; 49 Suppl 1:S151-S153.

27. Givon-Lavi N, D agan R, Fraser D, Yagupsky P, Porat N . Marked differences in pneumococcal carriage and resistance patterns between day care centers located within a small area. C lin Infect D is 1999;29(5):1274-1280. 28. Gray BM, Converse GM, III, Dillon HC, Jr. Epidemiologic studies of Streptococcus pneumoniae in infants: acquisition, carriage, and infection during the first 24 months of life. J Infect D is 1980; 142(6):923-933.

29. Fedson DS. Pneumococcal vaccines. In: Plotkin SA, Mortimer EAJ, editors. Vaccines. Philadelphia:W B Saunders, 1988: 271-299.

30. Tuomanen El, Masure HR. Molecular and cellular biology of pneumococcal infection. Microb D rug Resist 1997; 3(4):297-308.

31. D agan R, Leibovitz E, G reenberg D,Yagupsky P, Fliss D M, Leiberman A. Dynamics of pneumococcal nasopharyngeal colonization during the first days of antibiotic treatment in pediatric patients. Pediatr Infect $D$ is J 1998; 17(10):880-885 .

32. $\mathrm{N}$ ational Committee for Clinical Laboratory Standards. Performance standards for antimicrobial susceptibility testing. 2000.

33. Melander E, Molstad S, Persson K, H ansson HB, Soderstrom M, Ekdahl $K$. Previous antibiotic consumption and other risk factors for carriage of penicillin-resistant Streptococcus pneumoniae in children. Eur J Clin Microbiol Infect Dis 1998; 17(12):834-838.

34. Kislak JW, Razavi LMB, D aly AK, Finland M. Susceptibility of pneumococci to nine antibiotics. Am J Med Sci 1965; 250:262-268.

35. Appelbaum PC. Antimicrobial resistance in Streptococcus pneumoniae: an overview. Clin Infect $D$ is 1992; 15(1):77-83.

36. Smith AM, Klugman KP. Three predominant clones identified within penicillin-resistant South African isolates of Streptococcus pneumoniae. Microb Drug Resist 1997; 3(4):385-389.

37. Madhi SA, Petersen K, Madhi A, Khoosal M, Klugman KP. Increased disease burden and antibiotic resistance of bacteria causing severe community-acquired lower respiratory tract infections in human immunodeficiency virus type 1-infected children. C lin Infect D is 2000; 31(1):170-176. 38. Fenoll A, Jado I,Vicioso D, Pérez A, C asal J. Evolution of Streptococcus pneumoniae serotypes and antibiotic resistance in Spain: update (1990 to 1996). J Clin Microbiol 1998; 36(12):3447-3454.

39. Marton A, Gulyas M, Munoz R, Tomasz A. Extremely high incidence of antibiotic resistance in clinical isolates of Streptococcus pneumoniae in Hungary. I Infect D is 1991; 163(3):542-548.

40. Urbaskova P, Trupl J, Hupkova H, A ppelbaum PC, Jacobs MR. In vitro susceptibility of pneumococci to trovafloxacin, penicillin $G$, and other antimicrobial agents in the $\mathrm{C}$ zech Republic and Slovakia. Eur J C lin Microbiol Infect $D$ is 1996; 15(8):686-688.

41.Trupl J, Hupkova H, A ppelbaum PC, Jacobs MR. The incidence of penicillin-resistant pneumococci in the Slovak Republic. Pneumococcus Study Group. Chemotherapy 1997; 43(5):316-322.

42. Song JH, Lee N Y, Ichiyama S, Yoshida R, H irakataY, Fu W et al. Spread of drug-resistant Streptococcus pneumoniae in A sian countries:A sian $N$ etwork for Surveillance of Resistant Pathogens (AN SO RP) Study. C lin Infect D is 1999; 28(6):1206-1211.

43. Doern GV, Pfaller MA, Kugler K, Freeman J, Jones RN . Prevalence of antimicrobial resistance among respiratory tract isolates of Streptococcus pneumoniae in N orth A merica: 1997 results from the SEN TRY antimicrobial surveillance program. C lin Infect $D$ is 1998; 27(4):764-770.

44. D oern GV, Brueggemann AB, Blocker M, D unne M, Holley H P,Jr., Kehl $\mathrm{KS}$ et al. Clonal relationships among high-level penicillin-resistant Streptococcus pneumoniae in the United States. Clin Infect D is 1998; 27(4): 757-761.

45. McLaughlin VA, RileyTV, Roberts CL. Penicillin resistance in laboratory isolates of Streptococcus pneumoniae, in W estern Australia, 1990-1994. Eur J Epidemiol 1998; 14(6):611-615

46. Ho oefnagels-Schuermans A,Van Eldere J,Van Lierde S,Verbist L,Verhaegen J, Peetermans W E. Increase in penicillin resistance rates in Belgium due to clonal spread of a penicillin-resistant 23F Streptococcus pneumoniae strain. Eur J Clin Microbiol Infect D is 1999; 18(2):120-125.

47. O verweg K, Hermans PW, Trzcinski K, Sluijter M, de Groot R, H ryniewicz W. Multidrug-resistant Streptococcus pneumoniae in Poland: Identification of emerging clones. J Clin Microbiol 1999; 37(6):1739-1745.

48. Fluit AC, Jones ME, Schmitz FJ,A car J, G upta R,Verhoef J.Antimicrobial susceptibility and frequency of occurrence of clinical blood isolates in Europe from the SEN TRY antimicrobial surveillance program, 1997 and 1998. C lin Infect D is 2000; 30(3):454-460.

49. N esin M, Ramírez M, Tomasz A. C apsular transformation of a multidrug-resistant Streptococcus pneumoniae in vivo. J Infect D is 1998; 177(3): 707-713.

50. Ramírez M,Tomasz A.A cquisition of new capsular genes among clinical isolates of antibiotic- resistant Streptococcus pneumoniae. Microb Drug Resist 1999; 5(4):241-246.

51. Koornhof HJ,W asas A, Klugman K.Antimicrobial resistance in Streptococcus pneumoniae: a South African perspective. Clin Infect Dis 1992; 15(1):84-94.

52. McGee L, Klugman K, Tomasz A. Serotypes and clones of antibioticresistant pneumococci. In: Tomasz A, editor. Streptococcus pneumoniae. 
Molecular Biology \& Mechanisms of Disease. N ew York, NY: Mary Ann Liebert, Inc, 2000: 375-379.

53. McGee L, Klugman KP, Friedland D, Lee HJ. Spread of the Spanish multi-resistant serotype 23F clone of Streptococcus pneumoniae to Seoul, Korea. Microb Drug Resist 1997; 3(3):253-257.

54. Munoz R, Coffey TJ, Daniels M, D owson CG, Laible G, Casal J et al. Intercontinental spread of a multiresistant clone of serotype 23F Streptococcus pneumoniae.J Infect Dis 1991; 164(2):302-306.

55. Soares S, Kristinsson KG , Musser JM, Tomasz A. Evidence for the introduction of a multiresistant clone of serotype $6 B$ Streptococcus pneumoniae from Spain to Iceland in the late 1980s. J Infect D is 1993; 168(1):158-163. 56. Zighelboim S, Tomasz A. Penicillin-binding proteins of multiply antibiotic-resistant South African strains of Streptococcus pneumoniae. Antimicrob A gents Chemother 1980; 17(3):434-442.

57. Laible $G$, Spratt BG , H akenbeck R. Interspecies recombinational events during the evolution of altered PBP $2 x$ genes in penicillin-resistant clinical isolates of Streptococcus pneumoniae. Mol Microbiol 1991; 5(8):1993-2002. 58. Dowson CG, C offeyTJ, Spratt BG . O rigin and molecular epidemiology of penicillin-binding-protein- mediated resistance to beta-lactam antibiotics. Trends Microbiol 1994; 2(10):361-366.

59. Guenzi E, Gasc AM, Sicard MA, Hakenbeck R.A two-component signaltransducing system is involved in competence and penicillin susceptibility in laboratory mutants of Streptococcus pneumoniae. Mol Microbiol 1994; 12(3):505-515

60. Grebe T, Paik J, Hakenbeck R. A novel resistance mechanism against beta-lactams in Streptococcus pneumoniae involves $\mathrm{C}$ po A, a putative glycosyltransferase. J Bacteriol 1997; 179(10):3342-3349.

61. Smith AM, Klugman KP. N on-Penicillin-Binding protein mediated highlevel penicillin and cephalosporin resistance in a Hungarian clone of Streptococcus pneumoniae. Microb D rug Resist 2000; 6(2):105-110.

62. Echániz-Avilés $G$, Velázquez-Meza $M E, C$ arnalla-Barajas $M N$, Soto$N$ ogueron A, Di Fabio JL, Solórzano-Santos $F$ et al. Predominance of the multiresistant 23F international clone of Streptococcus pneumoniae among isolates from Mexico. Microb Drug Resist 1998; 4(3):241-246.

63. C astañeda E, Peñuela I,Vela MC, the Colombian pneumococcal study group and Tomasz A. Penicillin-resistant Streptococcus pneumoniae in $\mathrm{C}$ lombia: presence of international epidemic clones. Microb Drug Resist 1998; 4:233-239

64. Camou T, Hortal M,Tomasz A.The apparent importation of penicillinresistant capsular type 14 Spanish/French clone of Streptococcus pneumoniae into U ruguay in the early 1990s. Microb D rug Resist 1998;4(219):224. 65. Rossi A, Corso A, Pace J, Regueira M, Tomasz A. Penicillin-resistant Streptococcus pneumoniae in Argentina: Frequent occurrence of an internationally spread serotype 14 clone. Microb D rug Resist 1998; 4:225-231. 66. Tomasz A, Corso A, Severina EP, Echániz-A vilés G, Brandileone MC, Camou $T$ et al. Molecular epidemiologic characterization of penicillin-resistant Streptococcus pneumoniae invasive pediatric isolates recovered in six Latin-American countries: an overview. PAHO/Rockefeller University W orkshop. Pan American Health 0 rganization. Microb D rug Resist 1998; 4(3):195-207.

67. D agan R, Engelhard D, Piccard E, Englehard D. Epidemiology of invasive childhood pneumococcal infections in Israel.The Israeli Pediatric Bacteremia and Meningitis Group. JAMA 1992; 268(23):3328-3332.

68. McC racken GH, Jr. Etiology and treatment of pneumonia. Pediatr Infect $D$ is | 2000; 19:373-377.

69. Wubbel L, Muniz L, Ahmed A, Trujillo M, C arubelli C, McC oig C et al. Etiology and treatment of community-acquired pneumonia in ambulatory children. Pediatr Infect D is J 1999; 18(2):98-104.

70. W ald ER. Diagnosis and management of acute sinusitis. Pediatr Ann 1988; 17(10):629-638.

71.W ald ER. Sinusitis overview. Pediatr Ann 1998; 27(12):787-788.

72.W ald ER. Sinusitis. Pediatr Ann 1998; 27(12):811-818.

73. Giebink GS. Childhood sinusitis: Pathophysiology, diagnosis and treatment. Pediatr Infect D is J 1994; 13(1 Suppl 1):S55-S58.
74. Klein J0 0 titis media. C lin Infect D is 1994; 19(5):823-833.

75. Barnett ED, Klein J0. The problem of resistant bacteria for the management of acute otitis media. Pediatr Clin N orth Am 1995; 42(3): 509-517.

76. Musher $D, D$ agan $R$. Is the pneumococcus the one and only in acute otitis media? Pediatr Infect D is J 2000; 19(5):399-400.

77. Dagan R. Clinical significance of resistant organisms in otitis media. Pediatr Infect D is J 2000; 19(4):378-382.

78. Giebink GS. 0 titis media:The chinchilla model. Microb Drug Resist 1999; 5(1):57-72.

79. Daly KA, Hunter LL, G iebink GS. Chronic otitis media with effusion. Pediatr Rev 1999; 20(3):85-93.

80. Berman S. 0 titis media in children. N Engl J Med 1995; 332(23):15601565.

81. G ates GA. C ost-effectiveness considerations in otitis media treatment. O tolaryngol Head N eck Surg 1996; 114(4):525-530.

82.W orld Bank.W orld Development Report: Investing in Health. 0 xford Univ. Press, N ew York, 1993.

83. Bloom BR.The United States needs a national vaccine authority. Science 1994; 265(5177):1378-1380.

84. Robbins JB, A ustrian R, Lee C], Rastogi SC, Schiffman G, Henrichsen J et al. Considerations for formulating the second-generation pneumococcal capsular polysaccharide vaccine with emphasis on the cross-reactive types within groups.J Infect D is 1983; 148(6):1136-1159.

85. Fedson DS. Pneumococcal vaccination for older adults: the first 20 years. D rugs A ging 1999; 15 Suppl 1:21-30.

86. Fedson DS. Pneumococcal conjugate vaccination for adults: why it"s important for children. Pediatr Infect D is J 2000; 19(3):183-186.

87. Sankilampi U, Honkanen PO, Bloigu A, Leinonen M. Persistence of antibodies to pneumococcal capsular polysaccharide vaccine in the elderly.J Infect D is 1997; 176(4):1100-1104.

88. Sims RV, Steinmann W C, McC onville JH, King LR, Z wick W C, Schwartz $J S$. The clinical effectiveness of pneumococcal vaccine in the elderly. Ann Intern Med 1988; 108(5):653-657.

89. Farr BM, Johnston BL, C obb DK, Fisch MJ, Germanson TP,A dal KA et al. Preventing pneumococcal bacteremia in patients at risk. Results of a matched case-control study.Arch Intern Med 1995; 155(21):2336-2340.

90. Butler JC, Breiman RF, Campbell JF, Lipman HB, Broome CV, Facklam RR. Pneumococcal polysaccharide vaccine efficacy. $A n$ evaluation of current recommendations. JAMA 1993; 270(15):1826-1831.

91. Shapiro ED, Berg AT,A ustrian R, Schroeder D, ParcellsV, Margolis A et al.The protective efficacy of polyvalent pneumococcal polysaccharide vaccine. N Engl J Med 1991; 325(21):1453-1460.

92. Black $S$, Shinefield $H$. Issues and challenges: Pneumococcal vaccination in pediatrics. Pediatr Ann 1997; 26(6):355-360.

93. Fedson DS. The clinical effectiveness of pneumococcal vaccination: $A$ brief review.Vaccine 1999; 17 Suppl 1:S85-S90.

94. Germain RN , Hendrix LR. MHC class II structure, occupancy and surface expression determined by post-endoplasmic reticulum antigen binding. N ature 1991; 353(6340):134-139.

95. G arpenholt 0 , H ugosson S, Fredlund H, G iesecke J, 0 Icen P. Invasive disease due to $H$ aemophilus influenzae type $b$ during the first six years of general vaccination of Swedish children. Acta Paediatr 2000; 89(4): 471-474.

96. Shaheen MA, Frerichs RR,Alexopoulos N, Rainey J]. Immunization coverage among predominantly Hispanic children, aged 2-3 years, in central Los Angeles. Ann Epidemiol 2000; 10(3):160-168.

97. Dintzis RZ. Rational design of conjugate vaccines. Pediatr Res 1992. 32(4):376-385.

98. Butler JC, Breiman RF, Lipman HB, Hofmann J, Facklam RR. Serotype distribution of Streptococcus pneumoniae infections among preschool children in the United States, 1978-1994: implications for development of a conjugate vaccine. I Infect D is 1995; 171(4):885-889. 
99. Baltimore RS. N ew challenges in the development of a conjugate pneumococcal vaccine. JAMA 1992; 268(23):3366-3367.

100. Hausdorff W P, Bryant J, Kloek C, Paradiso PR, Siber GR. The contribution of specific pneumococcal serogroups to different disease manifestations: Implications for conjugate vaccine formulation and use, part II. Clin Infect D is 2000; 30(1):122-140.

101. HausdorffW P, Bryant J, Paradiso PR, Siber GR.W hich pneumococcal serogroups cause the most invasive disease: Implications for conjugate vaccine formulation and use, part I. C lin Infect D is 2000; 30(1):100-121. 102. Anderson EL, Kennedy DJ, Geldmacher KM, D onnelly J, Mendelman PM. Immunogenicity of heptavalent pneumococcal conjugate vaccine in infants. J Pediatr 1996; 128:649-653.

103. Dagan R, Melamed R, Zamir 0 , Leroy 0 . Safety and immunogenicity of tetravalent pneumococcal vaccines containing $6 \mathrm{~B}, 14,19 \mathrm{~F}$ and $23 \mathrm{~F}$ polysaccharides conjugated to either tetanus toxoid or diphtheria toxoid in young infants and their boosterability by native polysaccharide antigens. Pediatr Infect D is J 1997; 16(11):1053-1059.

104. Mbelle N, Huebner RE, W asas AD, Kimura A, Chang I, Klugman KP. Immunogenicity and impact on nasopharyngeal carriage of a nonavalent pneumococcal conjugate vaccine. J Infect D is 1999; 180(4):1171-1176.

105. Rennels MB, Edwards KM, Keyserling HL, Reisinger KS, Hogerman $D A$, Madore DV et al. Safety and immunogenicity of heptavalent pneumococcal vaccine conjugated to $\mathrm{CRM}_{197}$ in United States infants. Pediatrics 1998; 101:604-611.

106. Shinefield HR, Black S, Ray P, Chang I, Lewis N, Fireman B et al. Safety and immunogenicity of heptavalent pneumococcal $\mathrm{CRM}_{197}$ conjugate vaccine in infants and toddlers. Pediatr Infect D is J 1999; 18(9):757-763.

107. Black S, Shinefield H, Fireman B, Lewis E, Ray P, Hansen JR et al. Effica$c y$, safety and immunogenicity of heptavalent pneumococcal conjugate vaccine in children. N orthern California Kaiser PermanenteVaccine Study Center Group. Pediatr Infect D is J 2000; 19(3):187-195.

108. Eskola J, KilpiT, Palmu A, Jokinen J, H aapakoski J, Herva E et al. Efficacy of a pneumococcal conjugate vaccine against acute otitis media. $N$ Engl J Med 2001; 344(6):403-409.

109. 0 verturf $G D$ and the Committee on Infectious D iseases. A merican A cademy of Pediatrics. Technical report: Prevention of pneumococcal infections, including the use of pneumococcal conjugate and polysaccharide vaccines and antibiotic prophylaxis. Pediatrics 2000; 106:367-376.

110. Centers for Disease Control and Prevention. Preventing pneumococcal disease among infants and young children: Recommendations of the A dvisory Committee on Immunization Practices (ACIP). MMW R Morb Mortal W kly Rep 2000;49;1-34.

111. Lieu TA, Ray GT, Black SB, Butler JC, Klein JO, Breiman RF et al. Projected cost-effectiveness of pneumococcal conjugate vaccination of healthy infants and young children. JAMA 2000; 283(11):1460-1468.

112. Weycker $D$, Richardson $E, 0$ ster $G$. Childhood vaccination against pneumococcal otitis media and pneumonia: $A n$ analysis of benefits and costs. Am J Manag Care 2000;6:S526-S535.
113. Lieu TA, Black SB, Ray GT, Martin KE, Shinefield HR, W eniger BG.The hidden costs of infant vaccination. Vaccine 2000; 19(1):33-41.

114.Van D am JEG , Fleer A, Snippe H. Immunogenicity and immunochemistry of Streptococcus pneumoniae capsular polysaccharide.Antonie van Leeuwenhoek 58, 1-47. 1990.

115. N ahm MH, 0 lander JV, Magyarlaki M. Identification of cross-reactive antibodies with low opsonophagocytic activity for Streptococcus pneumoniae. J Infect D is 1997; 176(3):698-703.

116. O baro SK, Adegbola RA, Banya W A, Greenwood BM. Carriage of pneumococci after pneumococcal vaccination. Lancet 1996; 348(9022): 271-272.

117. D agan R, Givon-Lavi N ,Yagupsky P, et al. Effect of a 9-valent vaccine conjugated to CRN 197 (PnCCRM9) on nasopharyngeal (N P) carriage of vaccine type and non-vaccine type $S$. pneumoniae (Pnc) strains among day care center $(D C C)$ attendees. Program and Abstracts of the 38th Annual Interscience C onference on A ntimicrobial A gents and Chemotherapy, 1998. 118. Briles DE, H ollingshead S, Swiatlo E, Brooks-W alter A, et al. Pneumococcal proteins PspA and PspC:Their potential for use as vaccines. In: Tomasz A, editor. Streptococcus pneumoniae. Molecular Biology \& Mechanisms of Disease. N ew York, N Y: Mary Ann Liebert, Inc, 2000: 253-260.

119. Briles DE, Hollingshead S, Brooks-W alter $A, N$ abors $G S$, Ferguson $L$, Schilling $M$ et al.The potential to use PspA and other pneumococcal proteins to elicit protection against pneumococcal infection. Vaccine 2000; 18(16):1707-1711.

120. Briles DE, Hollingshead SK, N abors GS, Paton JC, Brooks-W alter A. The potential for using protein vaccines to protect against otitis media caused by Streptococcus pneumoniae.Vaccine 2000; 19 Suppl 1:S87-S95.

121. Lipsitch M. Bacterial vaccines and serotype replacement: lessons from Haemophilus influenzae and prospects for Streptococcus pneumoniae. Emerg Infect D is 1999; 5(3):336-345.

122. Eskola J, Anttila M. Pneumococcal conjugate vaccines. Pediatr Infect $D$ is ] 1999; 18(6):543-551.

123. Long SS.Antibiotic therapy in febrile children: " "best-laid schemes". J Pediatr 1994; 124(4):585-588.

124. Shrag SJ, Beall B, D owell SF. Limiting the spread of resistant pneumococci:Biological and epidemiologic evidence for the effectiveness of alternative interventions. Clin Microbiol Rev 2000; 13:588-601.

125. Coffey TJ, D owson CG, D aniels M, Z hou J, Martin C, Spratt BG et al. Horizontal transfer of multiple penicillin-binding protein genes, and capsular biosynthetic genes, in natural populations of Streptococcus pneumoniae. Mol Microbiol 1991; 5(9):2255-2260.

126. Daum RS. Pneumococcal vaccines for children: an update. Pediatr Infect D is | 1998; 17(9):823-824.

127. Musher, Breiman RF,TomaszA.Streptococcus pneumoniae:At the threshold of the 21st century. In:Tomasz A, ed. Streptococcus pneumoniae. Molecular Biology \& Mechanisms of D isease. N ew York: Mary Ann Liebert, Inc., 2000: 485-491. 